\title{
A IMPLEMENTAÇÃO DO CONSTRUTIVISMO EM ALFABETIZAÇÃO NA PERSPECTIVA DE FERREIRO E TEBEROSKY NA REDE MUNICIPAL DE ENSINO DE SÃO PAULO (1983-1988)
}

THE IMPLEMENTATION OF CONSTRUCTIVISM ON LITERACY FROM THE VIEWS OF FERREIRO AND TEBEROSKY IN THE EDUCATION SYSTEM OF SÃO PAULO CITY (1983-1988)

\author{
Fernando Rodrigues de Oliveira \\ Professor da Universidade Federal de São Paulo \\ fer.tupa@gmail.com \\ Diego Benjamim Neves \\ Mestrando em Educação pela Universidade Federal de São Paulo \\ dibenjamim@hotmail.com
}

\begin{abstract}
Resumo
Enfoca-se neste texto a implementação de prescrições construtivistas em alfabetização em documentos curriculares produzidos por equipes da Secretaria Municipal de Educação do Município de São Paulo, entre 1983 e 1988. Com objetivo de contribuir para a produção de uma História do ensino de leitura e escrita no Brasil, de modo a identificar e problematizar os sentidos das primeiras prescrições relativas ao construtivismo em alfabetização na rede municipal de ensino de São Paulo, selecionamos e analisamos sob a ótica da "configuração textual" alguns dos principais documentos nos quais se verificam processo de implementação do construtivismo em alfabetização nessa rede, em perspectiva eclética e conciliatória com pressupostos do interacionismo linguístico.
\end{abstract}

Palavras-chave: Alfabetização; Construtivismo; Rede Municipal de Ensino; São Paulo; História da educação.

\begin{abstract}
This text focuses on the implementation of constructivist prescriptions on literacy in the curricular documents produced by teams from the Department of Education of the city of São Paulo between 1983 and 1988. In order to contribute to the production of a History of the teaching of reading and writing in Brazil, to identify and problematize the meanings of the first constructivist prescriptions about literacy in the education system of the city of São Paulo, we selected and analyzed the textual configuration of the main documents related to the implementation of constructivism on literacy in this system, which took place in an eclectic and conciliatory way with the theory of linguistic interactionism.
\end{abstract}

Keywords: Literacy; Constructivism; Municipal Education Network; São Paulo; History of education. 


\section{Introdução}

A partir do final da década de 1970, com o gradativo processo de reabertura política do Brasil após o golpe militar que instituiu o regime ditatorial em 1964, o pensamento construtivista em alfabetização na perspectiva de Emilia Ferreiro e Ana Teberosky passou a ser amplamente difundido e adotado em diferentes localidades do país, como base para a reorganização da escola face ao novo momento político pelo qual se lutava (MORTATTI, 2000; MELLO, 2007).

A partir de ampla investigação sobre o fracasso escolar em alfabetização na América Latina, essas pesquisadoras argentinas publicaram, em 1979, o livro Los sistemas de Escritura en el desarollo del niño, no qual propõem uma "revolução conceitual" no campo da alfabetização (FERREIRO, 1985a), deslocando o eixo de discussão, antes centrado nos métodos "tradicionais" e no conceito de prontidão, para os pressupostos em torno da aprendizagem da lecto-escrita. Esse livro, publicado no México, logo passou a circular no Brasil, especialmente entre sujeitos ligados ao meio acadêmico, até ser traduzido em versão brasileira, em 1985, sob o título Psicogênese da língua escrita.

Desde que o pensamento construtivista em alfabetização de Ferreiro e Teberosky encontrou terreno fértil entre educadores e pesquisadores progressistas brasileiros, amplamente ligados ao movimento de luta pela redemocratização do país, tornou-se referência como alternativa educacional "contra-hegemônica"1 frente ao fracasso da escola em alfabetizar as crianças e possibilitar o acesso das camadas populares ao conhecimento nela veiculado.

Nesse movimento, como aponta Mortatti (2016), despontou a iniciativa de "primeira hora" de sujeitos ligados à Secretaria de Educação do Estado de São Paulo, que em 1983, durante a gestão do governador André Franco Montoro, instituíram o Ciclo Básico de Alfabetização, cujas mudanças incorporaram o construtivismo em alfabetização como a nova base teórico-metodológica da rede.

Ainda na década de 1980, com grandes investimentos financeiros e políticos das autoridades educacionais para convencimento sobre a relevância e viabilidade pedagógica do construtivismo (MORTATTI, 2016), as proposições de Ferreiro e Teberosky foram ganhando espaço e prestígio por todo o país, tornando-se a principal referência para a formulação de políticas curriculares nos estados e municípios, para o desenvolvimento de pesquisas acadêmicas em nível de pós-graduação e para a promoção de cursos de formação (inicial e em serviço) de professores. Como resultado, mediante as múltiplas apropriações que se foi fazendo dessa teoria, o construtivismo em alfabetização passou a constituir "senso comum pedagógico" no que tange ao ensino da leitura e da escrita, de modo a figurar como "consenso" no discurso e na prática docente de diferentes gerações de alfabetizadores e em políticas educacionais de amplitude nacional, logrando lugar de pensamento hegemônico sobre alfabetização na Educação brasileira (MORTATTI, 2016).

Em face desse movimento histórico, embora o construtivismo em alfabetização esteja em circulação no Brasil há quase quatro décadas e permaneça atuante e premente, seja em políticas curriculares, seja como objeto de investigação ou como referência teórico-conceitual na produção de conhecimento acadêmico-científico, ainda são escassos estudos mais pontuais², especialmente os de abordagem histórica, sobre a implementação, apropriação e usos dessa teoria nas prescrições de ensino nas diferentes redes.

1 Conforme propõe Saviani (2008), a análise das teorias pedagógicas na sua relação com a sociedade podem ser divididas em dois grandes grupos: "[...] aquelas que procuram orientar a educação no sentido da conservação da sociedade em que se insere, mantendo a ordem existente; e aquelas que buscam orientar a educação tendo em vista a transformação da sociedade, posicionando-se contra a ordem existente. As primeiras são chamadas "pedagogias hegemônicas" porque, correspondendo aos interesses dominantes, tendem a hegemonizar o campo educativo. As segundas transformar a ordem vigente". (p.11).

2 Como trabalho inaugural e de monta tem-se a pesquisa de Mortatti (2000), cujo recorte centra-se na rede Estadual de Educação de São Paulo. Além desse, destacamos os de Marinho (2001), Revah (2004), Mello (2007), Marsíglia (2011), Perisani (2014) e Carvalho (2016) por tratarem de aspectos relativos à circulação do pensamento construtivista em alfabetização no estado de São Paulo e sua implementação como discurso oficial. Cumpre destacar, porém, que desses trabalhos, apenas um deles volta-se à rede municipal de ensino de São Paulo, Carvalho (2016), porém o recorte temporal situa-se nos anos 2000. 
Por esse motivo, instados a pensar sobre questões envolvidas com a implementação do construtivismo em alfabetização nas políticas curriculares brasileiras a partir da década de 1980, como movimento de modernização do ensino sob o signo da redemocratização, apresentamos, neste texto, aspectos das prescrições para a alfabetização na rede municipal de ensino de São Paulo, entre 1983 e 1988, período em que essa teoria "chegou" às escolas paulistanas. Cumpre destacar que a opção por centrar a investigação nessa rede deveu-se principalmente a dois motivos: já à época tratava-se de uma das maiores redes de ensino do país; a proximidade com a rede estadual de ensino de São Paulo e com a iniciativas levadas a cabo nela, de forma pioneira.

Por isso, o objetivo central deste texto é contribuir para a produção de uma História do ensino de leitura e escrita no Brasil, de modo a identificar e problematizar os sentidos das primeiras prescrições relativas ao construtivismo em alfabetização na rede municipal de ensino de São Paulo.

Para a consecução desse objetivo, selecionamos e analisamos sob a ótica da "configuração textual"3 alguns dos principais documentos produzidos por equipes da Secretaria Municipal de Educação de São Paulo durante duas gestões municipais (1983-1985 e 1986-1988) e nos quais se verificam indícios e evidências da implementação do construtivismo em alfabetização nessa rede.

Como resultado dessa análise, organizamos este texto em cinco tópicos, além das considerações finais. No tópico inicial tratamos da reorganização do ensino municipal de São Paulo após a nomeação de Mário Covas Júnior como prefeito. No tópico seguinte, apresentamos a análise do currículo produzido em 1985, qual seja Programa de $1^{\circ} \mathrm{Grau}-1^{a}$ à $4^{a}$ série, destacando aspectos relativos às prescrições para o ensino da língua portuguesa/alfabetização. No terceiro tópico destacamos as principais mudanças ocorridas no ensino municipal de São Paulo após a volta de eleições diretas e a busca de propostas alternativas para a reconstrução do currículo. No quarto tópico analisamos dois documentos de natureza prescritiva sobre a alfabetização, produzidos entre 1986 e 1987, com intuito de implementar proposta de alfabetização centrada no pensamento de Ferreiro e Teberosky. No último tópico, estabelecemos análise comparativa entre os documentos estudados anteriomente, de modo a problematizar os mecanismos de implementação do construtivismo em alfabetização na rede municipal de ensino de São Paulo. Nas considerações finais elencamos os principais resultados obtidos em função do objeto da pesquisa. São, portanto, esses tópicos que passamos a apresentar a seguir.

\section{Reorganização “liberal democrática" do ensino municipal de São Paulo (1983-1985) e a produção de um novo currículo}

Em 1983, após a primeira eleição direta para governador no estado de São Paulo desde o início da ditadura militar, Mário Covas Júnior ${ }^{4}$, à época filiado ao Partido do Movimento Democrático Brasileiro (PMDB), foi nomeado prefeito da cidade de São Paulo por André Franco Montoro, então governador do Estado, após eleição indireta interna ao seu partido, disputada contra Orestes Quércia.

\footnotetext{
3 Por "configuração textual" entendemos a análise dos "[...] aspectos constitutivos de terminado texto, os quais se referem: o conjunto de aspectos constitutivos de determinado texto, os quais se referem: às opções temático-conteudísticas (o quê?) e estruturais-formais (como?), projetadas por um determinado sujeito (quem?), que se apresenta como autor de um discurso produzido de determinado ponto de vista e lugar social (de onde?) e momento histórico (quando?), movido por certas necessidades (por quê?) e propósitos (para quê), visando a determinado efeito em determinado tipo de leitor (para quem?) e logrando determinado tipo de circulação, utilização e repercussão." (MORTATTI, 2000, p. 31)

4 Mário Covas foi deputado federal por São Paulo nos períodos de 1963-1969 e 1983; prefeito de São Paulo São Paulo de 1983 a 1985; senador por São Paulo de 1987 a 1994 e governador do Estado de SP nos períodos de 1995 a 1998 e 1999 a 2001.
} 
Ao assumir o cargo, Mário Covas Júnior nomeou como Secretária de Educação a pesquisadora e professora universitária Guiomar Namo de Mello5, cuja missão, alinhada ao "governo democrático do PMDB", era implantar um projeto educacional de visão liberal centrado no tripé "Participação, democratização e trabalho técnico comprometido com a criança" (MELLO, 1983, p. 82-83).

Sob a gestão da nova secretária e sua equipe ${ }^{6}$, a Secretaria Municipal de Educação de São Paulo (SMESP) passou a estruturar suas ações em torno da construção de uma política educacional de democratização do acesso à escola, da melhoria da qualidade do ensino, da ampliação da permanência na escola, da melhoria das condições de trabalho do professor, da valorização do papel do professor nas decisões da rede e da recuperação da função social da escola como transmissora de conhecimento (SÃO PAULO, 1985a, p. I). Como resultado dessa política, foram desenvolvidas uma série de ações, dentre as quais, destacam-se: a reestruturação da carreira do magistério paulistano, a reformulação do Regimento Comum das escolas municipais, a realização de novos concursos para professores e diretores (o que não ocorria há décadas), a produção de novas orientações de acomodação da demanda de matrículas e o estabelecimento de novas diretrizes para gestão das escolas (SÃO PAULO, 1985a).

No que tange especificamente à "área pedagógica", como parte da política pautada na "valorização do servidor" e no entendimento do professor "como ponto de honra" (MELLO, 1983, p. 82), o Departamento de Planejamento e Orientação - DEPLAN, órgão vinculado à Secretaria Municipal de Educação de São Paulo, produziu, em 1985, um novo currículo para a rede, em versão preliminar, para substituir o que estava em vigor desde 1981. Esse novo currículo, intitulado Programa de $1^{\circ}$ Grau - $1^{a}$ à $4^{a}$ série - versão preliminar (1985), foi elaborado por equipes dos órgãos centrais ${ }^{7}$ e das escolas, envolvendo a participação de 12 coordenadoras pedagógicas ${ }^{8}$ da rede, além da colaboração especial da equipe de professores especialistas do Centro de Estudos Vera Cruz (CEVEC) e do Centro de Ensino de Ciências de São Paulo (CECISP).

Publicado em formato de apostila, com 113 páginas $^{9}$, Programa de $1^{\circ}$ Grau - $1^{a}$ à $4^{a}$ série - versão preliminar (1985) abrange as disciplinas de Língua Portuguesa, Matemática, Estudos Sociais e Ciências e Saúde e contém como anexo o detalhamento de cada programa dessas disciplinas, exceto língua portuguesa, e o programa de Educação Física. Com relação à organização, apresenta os seguintes tópicos: "Critérios norteadores na revisão do Programa de $1^{\circ}$ Grau"; "Considerações sobre o ensino de Língua Portuguesa no $1^{\circ}$ Grau"; "Considerações sobre o Programa de Língua Portuguesa na $1^{\mathrm{a}}$ e $2^{\mathrm{a}}$ série [sic]"; "Programa de Língua Portuguesa - $1^{\mathrm{a}}$ e $2^{\mathrm{a}}$ séries";

\footnotetext{
5 Formada em Pedagogia pela USP, Guiomar Namo de Mello tornou-se mestre em Educação, em 1976, pela PUC-SP, e doutora em Educação: História, Política e Sociedade, também pela PUC-SP, em 1980. Entre 1991 e 1992 fez estágio de pós-doutorado no Institute of Education da London University. Foi professora na PUC-SP entre 1967 e 1985, professora na Universidade Estadual de Campinas (UNICAMP), Universidade Federal de São Carlos (UFSCAR) e Universidade Federal de Minas Gerais (UFMG) e pesquisadora na Fundação Carlos Chagas. Elegeu-se Deputada Estadual em São Paulo, em 1986.

6 Durante a gestão de Guiomar Namo de Mello como secretária municipal de Educação, integraram a sua equipe: Teresa Roserley Neubauer da Silva, chefe de gabinete; Lisete Regina Gomes Arelaro, chefe da Assessoria Técnica; Eny Maria Maia, Superintendente de Educação; Marta Wolak Grosbaum, diretora do DEPLAN; e Hélio Maciel, Diretor do D.S.E.

7 No âmbito dos órgãos centrais, a elaboração do Programa de $1^{\circ}$ Grau - $1^{a}$ à $4^{a}$ série - versão preliminar (1985) foi coordenada por Maria Amábile Mansutti, com assessoria de Raquel Léa Brunstein, Sonia Teresinha de Sousa Penin e Yara Lúcia Esposito. A diretora do DEPLAN era Marta Wolak Grosbaum.

8 Eram as coordenadoras pedagógicas: Ana Maria F. de Carvalho, Ana Maria F. Lopes, Enedina Fonseca Redondo, Izabel Noriko Takejima Yoshinaga, Kity Kalepnieck, Lúcia Aparecida Moraes Terra, Maria Inês Pilon Souza Alves, Maria de Lourdes C. Toledo, Maria Silvia Cavasin Matanó, Rachel Portnoi, Regina Lúcia G. Perna, Vera Lúcia M. de Rafael

9 Esse documento teve tiragem de 1.000 exemplares na $1^{a}$ impressão e 500 exemplares na $2^{a}$ tiragem. Em 1985, a rede municipal de ensino de São Paulo era composta por 300 escolas de $1^{\circ} \mathrm{grau}$, com 10.649 professores em exercício, o que presume uso compartilhado ou coletivo do Programa de $1^{\circ} \mathrm{Grau}-1^{a}$ à $4^{a}$ série - versão preliminar.
} 
"Programa de Língua Portuguesa - $3^{a}$ e $4^{a}$ séries"; "Considerações sobre o ensino de Matemática no $1^{\circ}$ Grau"; "Programa de Matemática de $1^{a}$ à $4^{a}$ série"; "Considerações sobre o ensino de Língua Estudos Sociais no $1^{\circ}$ Grau"; "Programa de Estudos Sociais - $1^{a}$ à $4^{a}$ série"; "Considerações sobre o ensino de Ciências e Saúde no $1^{\circ}$ Grau"; "Programa de Ciências e Saúde - $1^{\text {a }}$ à $4^{a}$ série"; "Considerações gerais sobre a $1^{a}$ e $2^{a}$ séries" e "Considerações gerais sobre a $3^{a}$ e $4^{a}$ séries".

Figura 1 - Capa de Programa de $1^{0}$ Grau - $1^{a}$ à $4^{a}$ série - versão preliminar (1985)

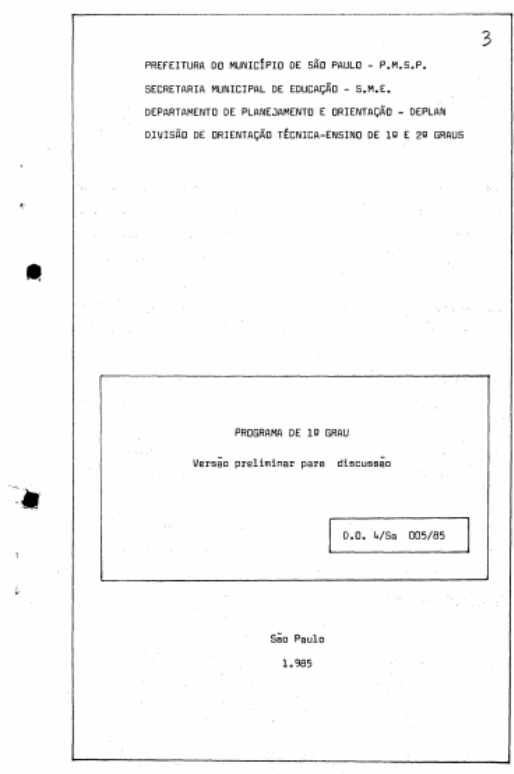

Fonte: SÃO PAULO (Município). Programa de $1^{\circ} \mathrm{Grau}$ - $1^{a}$ à $4^{a}$ série - versão preliminar. São Paulo: SME/DEPLAN, 1985a.

Sob a lema "Garantir ao maior número possível de crianças e jovens dos setores majoritários de nossa sociedade, a melhor escolarização possível" (SÃO PAULO, 1983, p. 5), o novo currículo do município de São Paulo, ainda que em versão preliminar, compreende um deslocamento em relação ao currículo até então vigente, tendo como fundamento o "[...] diagnóstico e interpretação das necessidades de aprendizagem dos alunos, tendo em vista suas características psico-econômico-culturais." (SÃO PAULO, 1985a, p. 5, grifos nossos).

A partir dessa nova visão, foram estabelecidos quatro critérios norteadores da nova proposta curricular, assim definidos: priorização da sequência lógica dos conhecimentos mais significativos de cada disciplina; compatibilização dos conhecimentos considerados indispensáveis para cada disciplina com a realidade dos alunos que frequentam a escola pública, de modo a estabelecer "equilíbrio" entre "dimensão lógica" e "dimensão psicológica"; estabelecimento de sequência e continuidade dos conhecimentos ao longo das séries, em perspectiva vertical, para garantia de similaridade no tratamento metodológico de cada disciplina; e adequação das prescrições de ensino às condições de trabalho do professor, seja pelo uso de linguagem usual a esses profissionais, seja pela proposição de procedimentos metodológicos intimamente relacionados aos conteúdos a serem desenvolvidos (SÃO PAULO, 1985a, p. 6).

O resultado desse processo correspondeu a um trabalho que ultrapassou a mera revisão da grade curricular. Tratou-se de reformulação de concepções político-pedagógicas, definição de conteúdos, estabelecimento dos métodos adequados e "[...] profunda revisão da natureza do trabalho docente" (SÃO PAULO, 1985b, p. 4). 


\section{As prescrições para 0 ensino da língua portuguesa em Programa de $1^{\circ} \mathrm{Grau}-$ $1^{a}$ à $4^{a}$ série, de 1985}

Alinhado à nova perspectiva curricular, o ensino da língua portuguesa é estabelecido em Programa de $1^{\circ}$ Grau - $1^{a}$ à $4^{a}$ série - versão preliminar (1985) com o objetivo de garantir-se na escola pública o acesso à norma culta da língua, "[...] por ser esta modalidade o veículo de aquisição e transmissão de conhecimentos acumulados pela sociedade, bem como instrumento de integração nacional" (SÃO PAULO, 1985a, p. 7). Portanto, a partir da "realidade" do aluno, entendida como a "modalidade linguística" por ele apresentada, o trabalho do professor devia voltar-se para o alcance da expressão "ideal”, correspondente ao domínio da "língua padrão".

Com isso, nas duas séries inicias, o conteúdo de língua portuguesa correspondia à "aquisição", "desenvolvimento" e "aperfeiçoamento" da leitura e da escrita, a alfabetização, e, nas duas séries seguintes, ao "domínio" da leitura e da escrita, da variação dos tipos de texto e dos recursos de linguagem.

Sob a lógica de "sequenciação vertical" do desenvolvimento dos conteúdos, a alfabetização é entendida nesse currículo como parte (etapa inicial) do ensino da língua portuguesa, não dissociada das etapas subsequentes, mas essencial e específica, pois também é a que possibilita aprender outros conteúdos de outras disciplinas.

Em virtude desse entendimento, explicita-se em Programa de $1^{\circ} \mathrm{Grau}$ - $1^{a}$ à $4^{a}$ série - versão preliminar (1985) que, no processo de alfabetização, as crianças apresentam "hipóteses" sobre as atividades de ler e escrever que não aparecem de forma igual e ao mesmo tempo para todas elas. Esse processo pode ir "[...] desde um estágio onde a escrita e desenho não são diferenciados até um ponto no qual a criança elabora uma hipótese alfabética sobre a escrita, ou seja, compreende que a escrita representa os sons de sua língua oral" (SÃO PAULO, 1985a, p. 10).

Com base nesse fundamento, embora o novo currículo defina alguns conteúdos a serem desenvolvidos em cada série, defende-se nele que o professor estabeleça as prioridades em função do levantamento das dificuldades das crianças, de modo a considerar a "experiência escolar" do aluno e sua "maturidade" (SÃO PAULO, 1985a).

Sobre a definição desses conteúdos, embora Programa de $1^{\circ}$ grau - $1^{a}$ à $4^{a}$ série - versão preliminar (1985) não se apresente como uma proposta de ensino em ciclos, as prescrições contidas neles estão estabelecidas de forma agrupada entre $1^{\mathrm{a}}$ e $2^{\mathrm{a}}$ séries e entre a $3^{\mathrm{a}}$ e $4^{\mathrm{a}}$ séries.

Para as duas séries inicias, que compreendem a fase da alfabetização, o ensino da língua portuguesa se organiza em torno de dois blocos de conteúdos "ouvir/falar" e "ler e escrever".

No bloco "ouvir/falar", prescrevem-se como conteúdos de ensino: valorizar a variedade linguística apresentada pelo aluno e o desenvolvimento da oralidade; atender às necessidades práticas da vida; e desenvolver a linguagem em direção à norma culta" (SÃO PAULO, 1985a, p. 17). Para o desenvolvimento desses conteúdos, indica-se como procedimentos metodológicos: trabalhar a distinção entre a natureza da fala e da escrita; criar condições para que a criança fale como sabe, sem desrespeitá-la ou criar juízo de valor; contar histórias, ouvir relatos, recitar poesias, cantar músicas e emitir opiniões sobre acontecimentos ou histórias; e favorecer a expressão do "ver", do "sentir" e do "saber" das crianças. 
No bloco "ler e escrever", prescrevem-se como conteúdos para a $1^{\text {a }}$ e $2^{a}$ séries: criar condições para a criança se aproximar e se adaptar com a linguagem escrita; criar condições cognitivas e psicomotoras para a aquisição da escrita; decompor e compor palavras; formar novas palavras; ler e escrever frases e pequenos textos; ler e escrever palavras em sílabas complexas; ler e produzir textos; fixar dificuldades ortográficas; desenvolver aspectos de natureza gramatical (concordância, pontuação e vocabulário); e desenvolver hábitos e habilidades essenciais para o uso social da escrita. Para o desenvolvimento desses conteúdos, são indicados um conjunto amplo de procedimentos metodológicos, que, de forma resumida, compreendem: trabalho que explore a vivência de uso e manuseio de impressos; vivência de situações que favoreçam a percepção do uso social da escrita; exploração de palavras significativas; uso dos recursos de decomposição de palavras por análise e síntese; observação da escrita para perceber semelhanças e diferenças em relação ao tamanho da palavras, à formação das sílabas e à posição que ocupam; e exploração do uso de textos somente após a criança dominar a escrita de palavras e avançar na compreensão das sílabas complexas.

Um aspecto importante a se destacar com relação aos procedimentos metodológicos do bloco de conteúdos "ler e escrever" para a $1^{a}$ e $2^{a}$ séries relaciona-se ao "erro" da criança. Conforme consta nessas prescrições, os erros manifestados pelos alunos durante o processo de escrita configuram-se como "construtivos", pois possibilitam compreender o modo como as crianças refletem o conhecimento que detêm.

Em relação às prescrições para o ensino da língua portuguesa na $3^{a}$ e $4^{a}$ séries, observa-se uma organização um pouco diferente, com três blocos de conteúdos, "ouvir/falar", "leitura" e "produção de texto", sem indicação explícita de procedimentos metodológicos.

Como conteúdos para o bloco "ouvir/falar" para a $3^{\mathrm{a}}$ e $4^{\mathrm{a}}$ séries prescrevem-se: estabelecer comunicação clara, criativa, espontânea e desembaraçada com o outro; atender às necessidades práticas da vida; e desenvolver uma linguagem próxima da norma culta. Para o bloco "leitura", prescrevem-se: ler para recrear-se, desenvolver o gosto, ampliar visão do mundo, dar vazão à emoção, recriar a realidade; ler para aperfeiçoar sua expressão oral e escrita, em relação à norma culta, percebendo a estrutura do texto, dentre o material sugerido em leitura livre, selecionado pelo professor ou alunos; e ler, sob orientação do professor, para buscar informações determinadas, confirmar dados de um experimento, enriquecer e sistematizar conhecimentos em textos didáticos, suplementos infantis, almanaques, enciclopédias infantis. Para o bloco "produção de texto", prescreve-se o trabalho com a escrita para: estabelecer uma comunicação, criativa e objetiva com o outro; atender às necessidades práticas da vida; registrar informações adquiridas; desenvolver uma linguagem próxima da norma culta; e desenvolver hábitos, habilidades e atitudes essenciais à escrita.

Ainda no ano de 1985, no mês de dezembro, após a implantação da versão preliminar de Programa de $1^{\circ} \mathrm{grau}-1^{a}$ à $4^{a}$ série, o DEPLAN publicou a versão definitiva desse currículo, com mesma denominação e com algumas alterações, decorrentes de apontamentos que os professores da rede fizeram a partir da versão preliminar. Essa versão definitiva foi publicada em volumes separados para cada série, contemplando as diferentes disciplinas escolares. 
Figura 2 - Capa de Programa de $1^{\circ}$ Grau - $1^{a}$ à $4^{a}$ série - versão definitiva (1985)
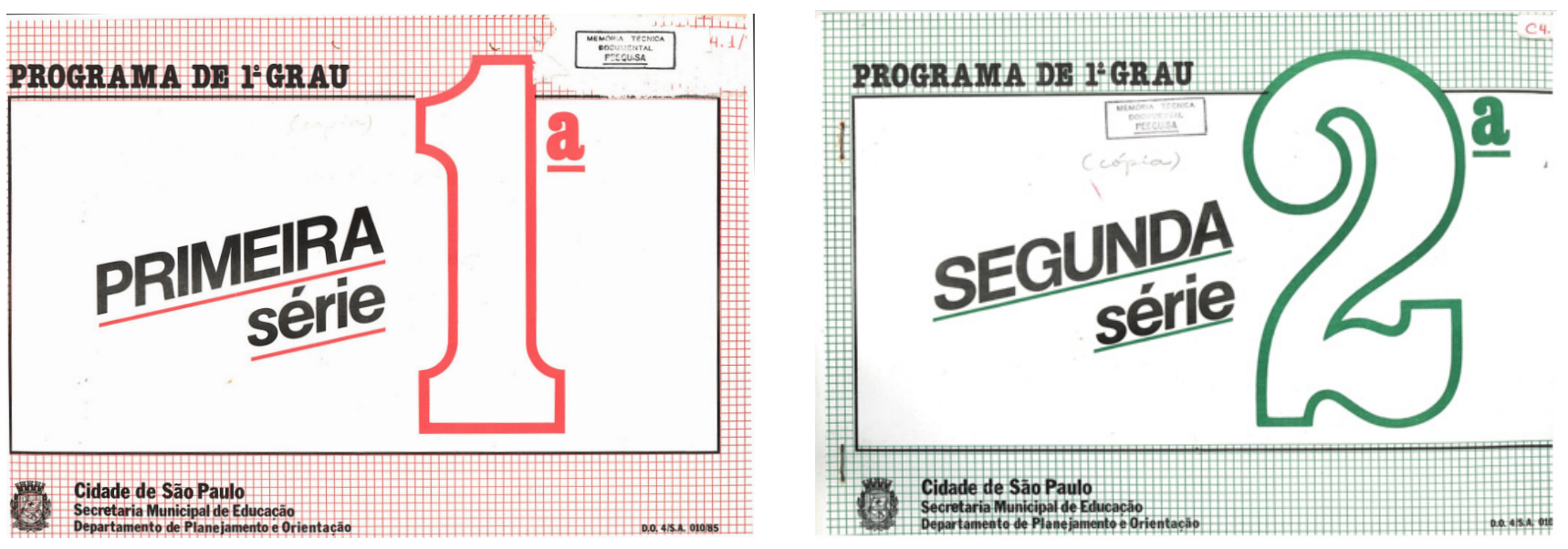

Fonte: SÃO PAULO (Município). Programa de $1^{\circ}$ Grau - $1^{a}$ à $4^{a}$ série. São Paulo: SME/DEPLAN, 1985b (versão definitiva).

Com relação à língua portuguesa, observa-se na versão definitiva de Programa de $1^{\circ}$ grau $1^{a}$ à $4^{a}$ série (1985) a manutenção dos pressupostos já apontados com relação à versão preliminar, porém, ganha espaço a perspectiva da "interação verbal", sintetizada na "prática de leitura de textos", "prática de produção de textos" e "prática de análise linguística de textos". É a partir dessas três práticas que os conteúdos são prescritos, de modo que as orientações metodológicas, embora não se opusessem às prescrições presentes na versão preliminar, são complementadas em face da visão interacionista sobre o ensino da língua. Essas prescrições para o ensino da língua portuguesa contidas na versão definitiva de Programa de $1^{o} \mathrm{grau}-1^{a}$ à $4^{a}$ série (1985) foram formuladas pelo DEPLAN com assessoria de João Wanderley Geraldi, Lilian Lopes Martins da Silva e Raquel Salek Fiad.

Apesar de haver mudanças em alguns aspectos prescritivos na versão definitiva de Programa de $1^{\circ} \mathrm{grau}-1^{a}$ à $4^{a}$ série, sua implantação na rede não se deu de modo efetivo, uma vez que foi publicado apenas em dezembro de 1985, quando encerrou-se a gestão de Mário Covas Júnior na Prefeitura de São Paulo.

\section{A reconfiguração "anti-ideológica" da Secretaria Municipal de Educação de São Paulo (1986-1988) e as novas diretrizes para 0 ensino}

Em janeiro de 1986, após 20 anos sem eleições municipais diretas, Jânio Quadros ${ }^{10}$, à época filiado ao Partido Trabalhista Brasileiro (PTB), iniciou o seu segundo mandato ${ }^{11}$ como prefeito de São Paulo (1986-1988), tendo derrotado 11 candidatos nas eleições de novembro de 1985.

Após assumir o cargo como prefeito, em 1986, por meio do decreto n. ${ }^{\circ} 21.862$, de 15 de janeiro, Jânio Quadros remodelou a Secretaria Municipal de Educação de São Paulo e condensou em uma única pasta as secretarias de Educação e Bem-Estar Social, tornando-a Secretaria Municipal de Educação e Bem-Estar Social (SME-BES).

10 Além de prefeito, Jânio Quadros foi governador do estado de São Paulo entre 1955 e 1959 e presidente da República por sete meses, em 1961, tendo renunciado ao cargo.

11 O primeiro mandato de Jânio Quadros ocorreu entre 1953 e 1954 e sua eleição para o segundo mandato compreendeu o período entre 1986 e 1988. 
Nessa nova estrutura, a SME-BES passou a conter duas superintendências: a Superintendência Municipal de Bem-Estar Social (SUBES) e a Superintendência Municipal de Educação (SUPEME), com um único secretário, o jornalista e escritor Paulo Zingg ${ }^{12}$.

De acordo com Plano de ação SUPEME: 1986/1988, de 1986, a integração da Superintendência Municipal de Bem-Estar Social à Superintendência Municipal de Educação teve como objetivo:

[...] garantir melhor aproveitamento de recursos humanos e igualdade de tratamento aos servidores da Educação e do Bem-Estar Social [...] para corrigir eventuais distorções, que [poderiam] gerar clima de indesejável conflito e insatisfação [...] com eventual redistribuição de pessoal [tendo] em vista um aproveitamento racional e equilibrado dos recursos humanos desses dois órgãos, essenciais à administração das creches e escolas municipais, em especial. Outro aspecto a ser considerado refere-se à necessidade de medidas voltadas à paridade salarial entre os servidores do mesmo nível e exercendo funções equivalentes [...] (SÃO PAULO, 1986a, p. 19).

Com a reconfiguração da SME-BES, foi nomeado para chefe da SUPEME o professor Sebastião Hermes Verniano ${ }^{13}$. Para ocupar o cargo de Diretora do DEPLAN foi nomeada Maria José Fonseca Barbosa e para ocupar a Diretoria de Divisão de Orientação Técnica de Ensino de $1 .{ }^{\circ}$ e $2 .{ }^{\circ}$ Graus foi nomeada Marlene de Paulo Lattouf.

Assim que esses profissionais assumiram esses cargos, a equipe vinculada a eles engendrou uma série de mudanças na Educação municipal, incluindo, sobretudo, as questões curriculares. A justificativa para essas mudanças decorreu da avaliação da nova gestão da SME-BES de que, à despeito do discurso "democrático" que marcou as políticas adotadas na gestão anterior, a ações levadas adotadas no governo de Mário Covas Júnior:

[...] evidenciaram medidas e atitudes autoritárias, centralizadoras, discriminatórias e clientelistas que geraram uma perda gradativa de confiança até nas propostas de natureza técnico-pedagógica. Um exemplo típico foi a resistência à aceitação das classes de desdobramento do processo de alfabetização, pedagogicamente válida, mas que foi interpretada, pela maioria das escolas, como 'mais um artifício' para mascarar o problema de retenção na primeira série. Esta percepção é claro indicador da pouca credibilidade da Administração anterior. (SÃO PAULO, 1986a, p. 1-2, grifos nossos).

Em função disso, uma das primeiras decisões tomadas pela nova equipe da SME-BES foi a recolha, ainda em 1986, do Programa de $1^{\circ} \mathrm{Grau}-1^{a}$ à $4^{a}$ série, produzido no final da gestão de Mário Covas, em 1985. Essa ação foi justificada pelos seguintes aspectos:

- Os princípios básicos subjacentes à proposta são universais e inquestionáveis, quais sejam: democratização do ensino, pela garantia de acesso e melhoria de qualidade, a ênfase à descentralização e participação de todos os educadores nas decisões, o resgate do papel social da escola e do professor. A maneira, contudo, como a programação foi proposta, evidencia uma postura tendenciosa, não apenas em suas origens filosóficas, mas a nível de ideologia político-partidária.

12 Autor de vários artigos, livros e tradutor, Paulo Zingg (1917-1991), ao longo de sua carreira, atuou em diferentes esferas do meio Educacional, entre as quais, destacam-se: Chefe de Gabinete da Secretaria Municipal de Educação de São Paulo entre 1949 e 1951 ; Diretor do Departamento de Educação e Recreio do município de São Paulo e Secretário de Educação e Cultura, entre 1969 e 1971 ; interventor e presidente da Fundação para o Livro Escolar do Governo do Estado de São Paulo, entre 1967 e 1972 ; e membro da Comissão Estadual de Moral e Civismo, entre 1962 e 1972. Dados os serviços prestados à Educação, em 1977 Paulo Zingg recebeu o título de Professor Emérito da cidade de São Paulo, concedido pela Ensino Municipal da Capital.

13 Até o momento de finalização deste texto, não foi possível identificar o nome do chefe da SUBES. 
- Quanto ao processo de sua elaboração e divulgação houve flagrante desrespeito aos educadores da Rede. A programação de $1^{a}$ à $4^{a}$ séries foi elaborada em três etapas, com consulta aos professores e tentativa de adequação às suas reivindicações, embora muitos questionamentos tenham sido deixados de lado por não atenderem à natureza da proposta original, segundo relatório dos próprios autores. A programação de $5^{a}$ à $8^{a}$ séries, com previsão para ser elaborada no mesmo sistema, teve sua elaboração apressadamente concluída, para garantir a distribuição ainda na Administração anterior. $O$ fato de o processo de consulta à Rede não ter sido levado a termo, muito embora a proposta tenha gerado uma série de controvérsias entre os professores, principalmente quanto à sua implantação em 1986, sem o necessário apoio administrativo, ou seja, preparo do professor para o desenvolvimento da programação de acordo com a metodologia explicitada, deixou de atender, também, às solicitações dos professores para discutirem mais profundamente questões quanto à sequenciação do conteúdo, notadamente em Estudos Sociais e Matemática e Metodologia em Língua Portuguesa. (SÃO PAULO, 1986a, p. 6-7, grifos nossos).

Essa decisão de recolher Programa de $1^{\circ}$ Grau - $1^{a}$ à $4^{a}$ série, de 1985, de todas as escolas municipais integrou um conjunto de ações ${ }^{14}$ entendidas como retrocesso no processo de democratização da educação paulistana, pois alteraram diretamente a construção coletiva das políticas educacionais para o município que se vinha produzindo desde os anos finais da ditadura militar (JACOMINI, 2016).

Como decorrência dessa forma de censura ao currículo anterior, entre 1986 e 1988 foi produzido um número bastante grande de material de natureza prescritiva e formativa para os professores, de modo a implantar uma nova perspectiva curricular, que se buscava coerente com os princípios políticos dessa gestão municipal.

No que se refere à produção de um novo currículo propriamente dito, entre 1986 e 1988 foram publicados: Programa de $1^{\circ}$ grau, com edições em 1986 e 1988 ${ }^{15}$; Proposta de Programação de Educação Infantil, com edição em 1987 e 1988'16; e Programa de primeiro grau - ensino regular: implementação, de 1987.

Além desses documentos, a SME-BES investiu de forma bastante contundente na construção de sua política educacional por outra via: a formação em serviço dos professores. Entre 1986 e 1988 essa secretaria promoveu 56 cursos para os professores da rede, totalizando a oferta de 14.327 vagas. Também foram realizadas capacitações iniciais para diretores, professores em geral, professores encarregados de sala de leitura, coordenadores pedagógicos e supervisores escolares, totalizando quase mil vagas.

Por causa desses cursos, seja para subsidiar a sua realização ou para possibilitar que os professores aplicassem os conteúdos neles ministrados, a SME-BES produziu um conjunto amplo de documentos entre 1986 e 1988, que embora não tivessem função curricular no sentido de prescrição de conteúdos, cumpriram importante papel na definição do "o que ensinar", "para que ensinar" e "como ensinar" no âmbito de determinadas áreas do conhecimento, dentre elas a alfabetização.

14 Dentre essas ações, destacam-se: o estabelecimento da centralização da gestão das escolas no diretor, a volta da indicação de especialistas pelo Executivo e a retomada de práticas de Educação Moral e Cívica (JACOMINI, 2016)

15 Programa de $1^{\circ} \mathrm{grau}$, de 1986, compreendia volumes de Português, Matemática, Ciências Físicas e Biológicas e da Saúde, Estudos Sociais, História e Geografia, Educação Artística, Educação Física e Inglês Quanto às tiragens: em 1986 publicou-se 10.000 mil exemplares de Português e 1988, 4.000; em 1986 publicou-se 10.000 exemplares de Matemática e em 1988, 3.000; em 1986 publicou-se 10.000 mil exemplares de Ciências Físicas e Biológicas e Saúde, e em 1988, 3.500; em 1986 publicou-se 10.000 mil exemplares de Estudos Sociais, História e Geografia, e em 1988, 6.000; em 1988 publicou-se 3.000 exemplares de Educação Artística; em 1988 publicou-se 8.900 exemplares de Educação Física, (1. ${ }^{a}$ e $2 .^{a}$ edições); em 1988 publicou-se 3.000 exemplares de Inglês.

16 Quanto às tiragens: em 1987 publicou-se 7.000 exemplares e em 1988, 2.800 exemplares. 


\section{A alfabetização no contexto da SME-BES (1986-1988)}

Como mencionamos, embora em 1986 a SME-BES tenha publicado um novo currículo para o município - Programa de $1^{\circ} \mathrm{grau}$, ele era destinado apenas às séries finais do ensino de $1^{\circ} \mathrm{grau}$. Portanto, não trata de questões propriamente ditas sobre a alfabetização.

Porém, ainda em 1986, com objetivo de sistematizar orientações gerais para o ensino da língua portuguesa em todas as séries do $1^{\circ} \mathrm{grau}$, foi publicado o documento Considerações gerais sobre 0 ensino de língua portuguesa, que apresenta "novas" diretrizes para esse ensino.

Esse documento, produzido e maio de 1986 pelo setor de Currículos, Programas, Métodos e Processos ${ }^{17}$ do DEPLAN, define uma "nova proposta metodológica" para o ensino do português, centrado nas "práticas" de leitura, de produção de texto e de análise linguística. Esse documento, fundamentado nos trabalhos O texto na sala de aula: Leitura \& Produção, de 1984, organizado por João Wanderley Geraldi, e A linguística e o ensino da língua portuguesa, de 1985, de Rodolfo llari, contém esclarecimento de que o trabalho a partir das "práticas" apresentava-se como proposta alternativa para o ensino da língua, mediante as "modernas teorias linguísticas", com o objetivo de corrigir as "falhas" da escola na consecução de seu objetivo primeiro: promover a aquisição da "[...] variedade padrão da língua, a partir da própria forma de expressão [dos alunos]." (SÃO PAULO, 1986b, p. 5).

De modo geral, Considerações gerais sobre o ensino de língua portuguesa define o que se entende pelas "três práticas" e apresenta fluxograma de como trabalhá-las no ensino da língua no $1^{\circ}$ grau. Como nele não há nenhuma observação específica sobre o trabalho por série, não se verifica atenção ou observação pontual sobre a alfabetização. Isso ocorreu em outro documento, publicado em abril de 1986, denominado Alfabetização - textos de apoio: língua portuguesa e matemática.

Produzido pelo setor de Treinamento e Aperfeiçoamento do DEPLAN, Alfabetização - textos de apoio: língua portuguesa e matemática ${ }^{18}$, como o título indica, apresenta textos de apoio ao trabalho do professor alfabetizador, de modo a definir "novas" orientações metodológicas específicas para o ensino inicial da leitura e da escrita. Em função disso, esse documento se organiza, no que concerne à língua portuguesa, da seguinte forma: texto inicial intitulado "O saber: uma dádiva ou uma construção?", de autoria da equipe do DEPLAN; esclarecimentos iniciais sobre ensino da Língua Portuguesa, também de autoria da equipe do DEPLAN; artigo intitulado "Deve-se ou não ensinar a ler na pré-escola? Um problema mal colocado"19, de autoria de Emilia Ferreiro; artigo intitulado "O desenvolvimento cognitivo e a prontidão para alfabetização" ${ }^{20}$, de autoria de Lúcia Lins Browne Rego; e artigo intitulado "Reflexões sobre algumas práticas escolares habituais", também de autoria da equipe do DEPLAN.

De modo geral, em Alfabetização - textos de apoio: língua portuguesa e matemática (1986), a partir dos pressupostos piagetianos sobre a epistemologia genética, tece-se um conjunto de críticas ao ensino em perspectiva transmissiva, que desconsidera o papel ativo do "sujeito cognoscente", as vivências geradoras de "conflitos cognitivos", o papel dos "estímulos" produzidos pelo ambiente e o funcionamento dos "esquemas assimiladores" no processo de aprendizagem.

17 Integravam a equipe de língua portuguesa desse setor: Célia Compagno Cyrino Pereira; Maria Regina Tordino; Roseney Rita Teggi Kotait; Maria Alice Tambelini Arnoni (Coordenadora da equipe).

18 Esse documento teve a $1^{a}$ tiragem com 1.000 exemplares e $2^{a}$ tiragem com 2.000 exemplares

19 Esse artigo de Ferreiro foi publicado originalmente no México em 1982 e integra o livro Reflexões sobre alfabetização, de 1985.

20 Lúcia Lins Browne Rego formou-se em Direito pela Universidade Federal de Pernambuco em 1969; em 1975 tornou-se mestre em Educação pela Tulane University e em 1991 doutorou-se em Psicologia do desenvolvimento. Esse texto de Lúcia Lins Browne Rego havia sido publicado no livro Aprender pensando, publicado pela Secretaria da Educação do Estado de Pernambuco, em 1983. 
Isso posto, o professor alfabetizador é definido como "auxiliar" ou "organizador" das situações que propiciam ao aluno "avançar", o que requer dele o entendimento sobre o complexo processo de aprendizagem do sistema de escrita, tal como propunham Emilia Ferreiro e Ana Teberosky em Los sistemas de escritura en el desarrollo del Niño (1979).

Em função dessa base conceitual, em Alfabetização - textos de apoio: língua portuguesa e matemática (1986) faz-se críticas ao uso das cartilhas e à manutenção do ensino "tradicional", centrado na leitura oralizada, na cópia, no ditado e no uso dos métodos de alfabetização. Em contraposição, aponta-se como alternativa o trabalho voltado para: a escrita espontânea, o desenvolvimento das atividades por meio de agrupamentos por nível de conhecimento, a leitura que privilegie a interpretação, a compreensão do "erro" como elemento "construtivo" e a valorização dos supostos "erros ortográficos" como elemento decisivo para compreender as "hipóteses sobre a escrita" que a criança apresenta.

Após a publicação de Alfabetização - textos de apoio: língua portuguesa e matemática, em fevereiro de 1987, o setor de Treinamento e Aperfeiçoamento do DEPLAN produziu um novo documento orientador sobre alfabetização, esse intitulado Propostas alternativas de alfabetização (destaque: Emilia Ferreiro) ${ }^{21}$. Esse documento contempla as principais ideias do construtivismo em alfabetização a partir dos "pressupostos de Emilia Ferreiro" e foi elaborado por um grupo específico de professores $^{22}$, sob assessoria de Esther Pillar Grossi, convidados para contribuir na formulação da "nova" política de alfabetização do município.

Para efetivar essa "proposta alternativa" e habilitar os professores ao uso dela, essa mesma equipe, ainda em 1987, promoveu um treinamento em serviço denominado "Alfabetização - processo e intervenção pedagógica", que consistiu em um curso de $12 \mathrm{~h}$ realizado nos meses de março a maio de 1987, tendo como público-alvo os professores de $1 .^{a}$ série da rede, totalizando 77 turmas de cursistas (SÃO PAULO, 1987b).

Com relação ao conteúdo de Propostas alternativas de alfabetização (destaque: Emilia Ferreiro) (1987), trata-se de um compilado da principais ideias veiculadas em Psicogênese da língua escrita (1985) e Reflexões sobre a alfabetização (1985), acompanhado do relato de seis professoras sobre a aplicação da "proposta alternativa" e 20 trabalhos de escrita de crianças da rede para exemplificar o que propõe a teoria construtivista.

Com relação às ideias de Emilia Ferreiro (e Ana Teberosky, embora o documento não faça menção a essa pesquisadora e coautora de Psicogênese da língua escrita), mediante o entendimento de língua como sistema de representação, aborda-se as hipóteses que a criança produz acerca do processo de aprendizagem da escrita, de modo a explicar como se constituem as "fases" pré-silábica, silábica e alfabética pelas quais toda criança passa. Defende-se em Propostas alternativas de alfabetização (destaque: Emilia Ferreiro) (1987) que era fundamental o professor alfabetizador conhecer esse processo evolutivo da aprendizagem da língua escrita, pois isso alterava de modo "revolucionário" o que se sabia até então sobre práticas de alfabetização.

A partir desses fundamentos "revolucionários", recomenda-se nesse documento que as propostas de alfabetização fossem reorientadas a partir do referencial construtivista, em oposição à ideia de "prontidão" e do ensino "tradicional", de modo que a escola constituísse "ambiente alfabetizado" para atender os alunos, especialmente os advindos de realidades sociais menos favorecidas.

21 Esse documento teve tiragem de 2.500 exemplares.

22 Participaram desse grupo 69 professores da rede municipal de ensino de São Paulo, contemplando escolas das cinco Diretorias Regionais de Ensino do Município (DREM) (SÃO PAULO, 1986c). 
Dessa forma, prescreve-se em Propostas alternativas de alfabetização (destaque: Emilia Ferreiro) (1987): a organização de materiais auxiliares, tais como, caixa de sucata, jornais, revistas, livros, cartaz de pregas, flanelógrafo, silabário do professor e aluno entre outros; organização de rotina diária e semanal de trabalho; diversificação do trabalho de forma individual, coletiva, e pequenos grupos; flexibilização de atividades, de modo que sirvam a diferentes contextos ou que sejam oferecidas de formas diferentes a partir das especificidades de cada aprendiz; e a organização diferenciada do espaço físico da sala de aula, a depender dos objetivos do professor (a sala de aula poderia ser organizada em círculo, semicírculo, em pares, fileiras ou em pequenos grupos, favorecendo interação social e as trocas entre as crianças).

Ainda com relação aos pressupostos teóricos e às prescrições postuladas em Propostas alternativas de alfabetização (destaque: Emilia Ferreira), mesmo com as críticas ao ensino "tradicional", defende-se o uso dos princípios de análise e síntese na escrita de palavras (o que não corresponde exatamente aos métodos), pois eram considerados fundamentais para que a criança compreenda a relação grafo-fonêmica da escrita alfabética:

\begin{abstract}
Um trabalho de análise e síntese de palavras, com os alunos que estão em níveis de escrita mais avançados (silábicos-alfabéticos e alfabéticos), através: da divisão de palavras em sílabas escritas; de atividades para conservação das sílabas; da decomposição e composição de palavras. Um trabalho que procura informar, mais sistematicamente, sobre a escrita convencional, dirigido aos alunos que estão com uma escrita no nível alfabético. (SÃO PAULO, 1987a, p. 4).
\end{abstract}

Após definidos os pressupostos teóricos e algumas prescrições concernentes à "proposta alternativa" de alfabetização, esse documento contempla o depoimento de seis professoras da rede que "aplicaram" a nova proposta, de forma a demonstrar a viabilidade e eficiência da mudança pedagógica proposta pela SME-BES. Com relação a esses depoimentos, as professoras destacam que a "nova proposta" mudaram o modo como elas compreendiam e passaram a desenvolver as práticas de alfabetização, sobretudo em função dos seguintes aspectos: o reconhecimento do papel do professor como "mediador" entre "o aprendiz e a escrita"; a importância do reconhecimento da criança como sujeito ativo de seu processo de aprendizagem; a mudança propiciada pelas descobertas de Ferreiro, em especial sobre como a criança aprende a ler e escrever e como se desenvolvem as hipóteses formuladas por elas sobre a escrita; o prazer de "ensinar" de forma "não tradicional"; e a perda de sentido das cartilhas, do período preparatório e de tudo que se associa aos "métodos tradicionais".

Também no ano de 1987, após a publicação de Propostas alternativas de alfabetização (destaque: Emilia Ferreira) (1987), a equipe do DEPLAN publicou outras orientações didáticas em relação à alfabetização, essas organizadas em dois volumes ${ }^{23}$, e publicou um novo currículo para língua portuguesa: Programa de primeiro grau - ensino regular: implementação de português.

Esse novo currículo, publicado no Diário Oficial do município em abril de 1987, apresenta de forma detalhada prescrições para o ensino da língua portuguesa da $1^{a}$ à $8^{a}$ série do ensino de $1^{\circ}$ grau. Para isso, esse documento organiza os conteúdos com base nas "práticas de leitura", "práticas de produção de texto" e "práticas de análise linguística", com recomendação, ao final, de livros literários que poderiam ser utilizados em cada série.

23 São essas coletâneas: Alfabetização: reflexões sobre algumas práticas escolares: leitura, cópia, ditado, escrita espontânea - erro e correção, trabalho grupal, atividades de livre-escolha; e Alfabetização: produção de texto; trabalho com palavras e letras. 
Importante notar em Programa de primeiro grau - ensino regular: implementação de Português (1987) que somente para o eixo de conteúdos da "prática de leitura" as prescrições se dão divididas por série. Nos outros eixos não há distinção entre as séries do $1^{\circ}$ grau. Outro aspecto a ser destacado é que nas prescrições contidas no eixo "prática de análise linguística" consta tópico específico sobre alfabetização, intitulado "Compreensão da estrutura do sistema de escrita", no qual são detalhados os pressupostos teóricos da psicogênese da língua escrita de Ferreiro e Teberosky.

De modo geral, o que se verifica em Programa de primeiro grau - ensino regular: implementação de Português (1987) é a manutenção dos pressupostos construtivistas para a alfabetização que constam nos documentos publicados anteriormente, porém, agora associado à perspectiva interacionista da linguagem, adotada como fundamento maior para o ensino da língua portuguesa em todo o $1^{\circ} \mathrm{grau}$.

Após a publicação desse novo currículo, em 1988, com conteúdo bastante similar ao dos documentos anteriores, porém com aprofundamento de algumas questões, o DEPLAN publicou o documento Alfabetização: os primeiros dias de aula na $1^{a}$ série do $1^{\circ} \mathrm{Grau}$, como forma de orientar os professores na efetivação do currículo e encerrando ciclo de prescrições relativas à alfabetização em face da "proposta alternativa" sintetizada no pensamento construtivista Ferreiro e Teberosky sobre a aprendizagem da língua escrita.

\section{0 construtivismo em alfabetização na rede municipal de ensino de São Paulo: dos primeiros indícios à implementação como proposta alternativa}

Ao analisar as prescrições para a alfabetização produzidas no âmbito das políticas curriculares da Secretaria Municipal de Educação de São Paulo, entre 1983 e 1988, é possível identificar alguns dos principais aspectos que estiveram envolvidos com a "chegada" do construtivismo em alfabetização no contexto paulistano, de forma a identificar os modos pelos quais essa teoria foi sendo incorporada ao discurso da rede.

Com a ascensão do PMDB ao governo estadual de São Paulo, em 1983 e, consequentemente, à prefeitura da capital paulista, sob o signo da democratização, as iniciativas de reorientação do ensino municipal buscaram aproximação e a incorporação do discurso acadêmico "de ponta" (MORTATTI, 2000) como referência a um "novo" conceito de "competência" para a definição dos gestores educacionais (MELLO, 1983). Essa relação entre Academia e escola básica teve como um de seus pilares a busca por teorias alinhadas a uma visão liberal, que possibilitasse a reconstrução do país mediante reconstrução da escola como lugar de superação das desigualdades sociais agravadas com o regime ditatorial e a garantia de igualdade de acesso ao saber sistematizado. Esse aspecto se evidencia, por exemplo, no discurso de posse de Guiomar Namo de Mello como Secretária Municipal de Educação, publicado no periódico Cadernos de Pesquisa, em 1983.

Sobre essa relação entre Academia e escola básica, o que se verifica no município de São Paulo em 1983 é que o primeiro escalão da Secretaria Municipal de Educação advinha de formação e atuação em universidades e instituições de pesquisa da capital paulista, em especial a Pontifícia Universidade Católica (PUC-SP) e a Fundação Carlos Chagas. À época, Guiomar Namo de Mello, Secretária Municipal de Educação, Teresa Roserley Neubauer da Silva, chefe de gabinete, Marta Wolak Grosbaum, diretora de DEPLAN, e Yara Lúcia Espósito, principal assessora na elaboração do Programa de $1^{\circ} \mathrm{Grau}-1^{a}$ à $4^{a}$ série - versão preliminar (1985), integravam o Departamento de Pesquisas Educacionais da Fundação Carlos Chagas. Todas elas, exceto Teresa Roserley Neubauer, também se formaram em nível de graduação e/ou pós-graduação pela PUC-SP. 
No interior desse movimento de incorporação do discurso acadêmico pelo discurso oficial da administração pública em educação, a alfabetização passou a ser reconhecida como questão estratégica na construção dos princípios democráticos para uma "nova qualidade" em Educação, o que demandava uma política de formação e convencimento dos professores e não a imposição do novo (MORTATTI, 2000). Nesse sentido, conforme se explicita em Programa de $1^{\circ} \mathrm{Grau}-1^{a}$ à $4^{a}$ série - versão preliminar (1985), a sua formulação ocorreu com base em:

[...] processo coletivo que envolveu todos os dirigentes dos órgãos centrais de S.M.E., equipes do DEPLAN e das DREMs, equipe das escolas e grupos ligados à Universidade e a experiências pedagógicas bem sucedidas, tanto no ensino público quanto do particular (SÃO PAULO, 1985a, p. III).

Pelo lugar estratégico que o ensino da língua ocupava nesse projeto de "nova qualidade" para a educação paulistana, o seu programa foi o que mais sofreu alteração em relação aos que vigoraram até o início da década de 1980. Não por acaso, conforme consta na versão definitiva de Programa de $1^{\circ} \mathrm{Grau}-1^{a}$ à $4^{a}$ série (1985), essas prescrições foram também as que sofreram as maiores críticas e apontamentos por parte dos professores da rede:

[...] à Língua Portuguesa pôde-se constatar tanto através dos registros recebidos, como por ocasião do retorno das equipes escolares ao DEPLAN, que foi o componente que gerou mais polêmica e recebeu maior número de sugestões de alterações. Esse resultado já era esperado, uma vez que, dos Programas discutidos, o de Língua Portuguesa era o que continha maior grau de inovação. (SÃO PAULO, 1985b, p. 3)

Essas inovações, tal como apresentamos, se orientam na definição do "o que ensinar" em função de um novo vetor - "para que se aprende" (SÃO PAULO, 1985b), cujos indícios ${ }^{24}$ denotam deslocamento para adoção de alguns dos pressupostos construtivistas de Ferreiro e Teberosky.

Ao analisarmos Programa de $1^{\circ} \mathrm{Grau}-1^{a}$ à $4^{a}$ série - versão preliminar (1985), é possível compreender que o ensino da língua portuguesa se pauta na concepção de língua como sistema de representação, ou seja, sistema inventado coletivamente pela humanidade (filogênese), em oposição ao pensamento corrente da época, que definia a língua como sistema de código. Esse aspecto é um dos fundamentos de reorientação do construtivismo em alfabetização, pois coloca no centro da cena a valorização do saber linguístico da criança e possibilita compreender o processo de aprendizagem em linha evolutiva regular da modalidade escrita da língua.

Nesse sentido, se verifica em Programa de $1^{\circ} \mathrm{Grau}-1^{a}$ à $4^{a}$ série - versão preliminar (1985) observação com relação às hipóteses das crianças sobre as atividades de ler e escrever, como processo individual de reconstrução da evolução da escrita (ontogênese). A explicação que se tem nesse documento é a de que, de um estágio inicial no qual para a criança não há diferenciação entre desenhos e letras, ela evolui para a compreensão da escrita como representação dos sons da fala.

Outro aspecto concernente ao construtivismo em alfabetização que se observa nas prescrições curriculares de 1985 é o estabelecimento de alguns pressupostos da teoria da inteligência, postulada por Jean Piaget, que sustenta o fundamento psicogenético do pensamento de Ferreiro e Teberosky.

24 Indícios é aqui entendido no sentido proposto por Ginzburg (1989), como elementos que permitem a identificação de distinção de traços, que marcam a individualidade das coisas e dos sujeitos. Esse conceito, tal como explica Ginzburg, tem seus fundamentos no método indiciário desenvolvido pelo crítico de arte Giovanni Morelli. 
Conforme se verifica em Programa de $1^{\circ} \mathrm{Grau}-1^{a}$ à $4^{a}$ série - versão preliminar (1985), a partir da compreensão evolutiva da inteligência, preconiza-se a ideia de que a diversidade de estágios dos "níveis de conhecimento" que as crianças demonstram na escola se relacionam às "[...] defasagens em termos de ritmos evolutivos que separam, por exemplo, uma criança da classe média de uma criança que vive num meio sócio-econômico desfavorecido (SÃO PAULO, 1985a, p. 10). Ou seja, as diferentes condições para a criança "assimilar" informações estão diretamente associadas aos estímulos que ela recebe a partir do meio em que vive e/ou do qual se origina. Entende-se, com isso, que todas as crianças apresentam condições iguais de "assimilar informações", porém se faz necessário a adequação dos estímulos para desenvolvimento de "[...] pré-requisitos linguísticos, cognitivos e psico-motores [...]" (SÃO PAULO, 1985a, p. 10).

Outros dois conceitos decorrentes do construtivismo em alfabetização de Ferreiro e Teberosky observáveis em Programa de $1^{\circ}$ Grau - $1^{a}$ à $4^{a}$ série - versão preliminar (1985) são "conhecimento espontâneo" e "erro construtivo". Esses conceitos, também advindos da teoria da inteligência de Piaget, aparecem de modo diluído nesse programa, como pressupostos inerentes à concepção de alfabetização nele preconizada.

Sobre "conhecimento espontâneo", verifica-se em Programa de $1^{\circ}$ Grau - $1^{a}$ à $4^{a}$ série - versão preliminar prescrições de valorização e aceitação do saber que a criança traz para a escola, de modo a estimular a sua participação ativa e espontânea em atividades de oralidade, de leitura e de escrita. A valorização do conhecimento espontâneo por parte de Ferreiro e Teberosky deve-se ao fato de que por meio dele é possível identificar a originalidade de ideias que as crianças manifestam sobre a língua, como conhecimento próprio, que marca o seu lugar como "sujeito cognoscente" e redefine o papel do professor como mediador na construção de estímulos para o desenvolvimento da aprendizagem. Sobre esse aspecto, em Programa de $1^{\circ} \mathrm{Grau}-1^{a}$ à $4^{a}$ série - versão preliminar (1985) recomenda-se o seguinte:

É importante que o professor incentive a participação ativa da criança em todas as atividades propostas. Essa atitude traduz um respeito à criança enquanto sujeito que pensa e que tem um saber próprio, possibilitando ao professor não só se informar sobre esse conhecimento, com também entender como a criança o elabora (SÃO PAULO, 1985a, p. 15).

Sobre o conceito de "erro", na lógica construtivista, seu entendimento está à serviço da compreensão da natureza e das razões pelas quais a criança "erra". Não se trata simplesmente de identificar e apontar o "erro", mas utilizá-lo como base para o processo de aprendizagem pautado na desestabilização das hipóteses sobre a escrita. Por isso, explica-se em Programa de $1^{\circ} \mathrm{Grau}-1^{a}$ à $4^{a}$ série - versão preliminar (1985) que:

[...] "erro" reflete o nível de compreensão que [a criança] está tendo sobre a escrita, cabendo lembrar que a única referência concreta que possui é a linguagem oral por ela utilizada (pronúncia). Estes "erros" são construtivos e necessários na medida em que retratam seu modo de refletir. Portanto, a avaliação da escrita não deve ser tão rígida a ponto de ser considerada apenas seus aspectos normativos (grafia, acentuação), deve-se considerar também o conteúdo das mensagens e a forma como a criança se expressa. (SÃO PAULO, 1985a, p.16).

Em relação à versão definitiva de Programa de $1^{\circ} \mathrm{Grau}-1^{a}$ à $4^{a}$ série, publicada em dezembro de 1985, embora seu uso não tenha se efetivado na rede, pois foi recolhida já no início de 1986, sua formulação aponta para um aspecto importante como tendência das políticas curriculares sobre alfabetização no município: o ecletismo teórico-metodológico. 
Como apontamos, na versão definitiva desse programa verifica-se a manutenção dos pressupostos construtivistas, porém justapostos à perspectiva do interacionismo linguístico. A centralidade desse programa se dá nas práticas de leitura, produção e análise linguística de textos, tendo como principal fundamento a concepção de linguagem como meio e resultado das interações.

Nos termos em que essas teorias são postas na versão definitiva de Programa de $1^{\circ} \mathrm{Grau}-1^{a}$ à $4^{a}$ série (1985), esse ecletismo pode ser entendido como "[...] processos socioculturais nos quais estruturas ou práticas discretas, que existiam de forma separada, se combinam para gerar novas estruturas, objetos e práticas" (CANCLINI, 2001, p. xix) sem necessariamente considerar ou preservar distinções e contradições existentes entre elas. Sobre isso, embora tanto o construtivismo quanto o interacionismo se configurassem, à época, como "teorias contra-hegemônicas", por se oporem à ordem vigente, elas adivinham de posicionamentos políticos e teórico distintos, os quais foram sendo naturalizados e colocados lado a lado, em justaposição, como complementares entre si (MORTATTI, 2000; 2016).

A partir do ano de 1986, quando a equipe nomeada por Jânio Quadros assumiu a Secretaria Municipal de Educação e iniciou processo de mudanças na política curricular, sob alegação de suprimir a "ideologia partidária" do governo anterior, o que se observa em relação à alfabetização é a explícita adoção do construtivismo em alfabetização como referência para toda a rede.

Já com as traduções em português de Psicogênese da língua escrita e Reflexões sobre a alfabetização, ambas de 1985, os documentos produzidos entre 1986 e 1988 na rede municipal de ensino de São Paulo apresentam esses livros como referência para as proposições contidas neles, de tal modo que definem as novas prescrições como a "proposta alternativa de Emilia Ferreiro".

Sob assessoria de Esther Pillar Grossi, uma das pioneiras no estudo e disseminação do pensamento de Ferreiro e Teberosky no Brasil, as prescrições para alfabetização produzidas entre 1986 e 1988 indicam adensamento dessa perspectiva nas políticas curriculares da rede, com discurso bastante enfático sobre a relevância e primazia da "nova" proposta "alternativa".

Para reforçar esse discurso, nesse período ocorreram investimentos de formação em serviço dos professores, para promover a efetivação e aceitação da nova proposta e como decorrência foram produzidos materiais que visavam a esclarecer, em detalhes, a "proposta alternativa" de alfabetização com "destaque" para Ferreiro (e Teberosky).

Como principais aspectos do aprofundamento da proposição do construtivismo em alfabetização na política curricular da rede municipal de ensino de São Paulo entre 1986 e 1988 tem-se: a crítica à noção de "maturidade" e "prontidão"; a proposição de uma didática que contemple o trabalho coletivo para viabilizar a socialização e as trocas de experiências (o que posteriormente ficou conhecido, de modo rotineiro, como agrupamentos produtivos); a crítica explícita aos métodos "tradicionais" e ao uso das cartilhas; a exploração do conceito de conflito cognitivo para criar situações que oportunizam o desenvolvimento e a aprendizagem; a defesa em torno da valorização e reconhecimento do pensamento infantil; proposição de trabalho que estimule e tome como referência diagnóstica as escritas espontâneas e os "erros"; e a construção de "ambientes alfabetizadores", com recursos variados de circulação e uso social da escrita, para estímulo ao desenvolvimento.

Em relação ao interacionismo linguístico, conforme apresentamos, alguns dos seus pressupostos, especialmente as "três práticas", figuram em alguns documentos publicados entre 1986 e 1988, especialmente em Programa de primeiro grau - ensino regular: implementação de Português (1987). 
Nele, as prescrições para o ensino da língua portuguesa para todo o ensino de $1^{\circ} \mathrm{grau}$ se estruturam a partir dos pressupostos do interacionismo linguístico, com referência a um dos trabalhos inaugurais dessa proposta, O texto na sala de aula: Leitura \& Produção (1984), de João Wanderley Geraldi. Esse aspecto reforça a interpretação sobre o ecletismo das proposições conciliatórias entre interacionismo e construtivismo na rede municipal de ensino, contudo, é indicativo também de outro elemento constituinte desse ecletismo: de que as proposições construtivistas se voltavam ao ensino inicial da língua portuguesa, como etapa de "aquisição" da língua escrita e compreensão do princípio alfabético dela, enquanto que as "práticas" de leitura, produção e análise linguística de textos se aplicavam propriamente aos que já dominavam esse princípio alfabético. Não por acaso, conforme apontamos, em Programa de primeiro grau - ensino regular: implementação de Português (1987) somente para a prática de leitura há distinção de conteúdos por séries, prevalecendo conceitos construtivistas nas séries iniciais. Também para o eixo de análise linguística entende-se que a primeira etapa corresponde à compreensão do sistema de escrita, explicitado a partir dos fundamentos construtivistas, para somente depois se abordar a "análise textual" e "análise gramatical" (SÃO PAULO, 1987b).

Sobre essa hipótese é importante destacar que as proposições centradas no construtivismo em alfabetização contidas nos documentos publicados entre 1986 e 1988 pela SME-BES não desconsideram proposições que envolvam o trabalho com leitura e escrita de frases, pequenos textos ou uso de livros e impressos variados. Porém, essas proposições se dão todas elas em função da "aquisição" da hipótese alfabética da escrita e, portanto, o domínio da lecto-escrita.

Em face do exposto, é possível afirmar que o modo como o construtivismo em alfabetização consta nas publicações da SME-BES a partir de 1988 configura movimento de implementação dessa teoria nas políticas curriculares da rede, concorrendo "[...] à disputa pela hegemonia do novo [...]" (MORTATTI, 2000, p. 253).

\section{Considerações Finais}

Por meio dos resultados da análise da configuração textual dos documentos aqui apresentados, é possível compreender alguns dos principais sentidos envolvidos com as primeiras prescrições construtivistas para a alfabetização na rede municipal de ensino de São Paulo, entre 1983 e 1988, no contexto de reconstrução democrática do Brasil.

Nesse período, observa-se, inicialmente, a adoção de alguns pressupostos teóricos do pensamento de Ferreiro e Teberosky na definição do novo currículo da rede, em 1985, sem menção declarada a essas pesquisadoras ou à teoria cunhada por elas e sintetizada em Los sistemas de Escritura en el desarollo del niño (1979). Essa situação mudou significativamente a partir de 1986, quando a rede assumiu a defesa por uma "proposta alternativa" de alfabetização, com "destaque" e centralidade para as formulações de "Emilia Ferreiro".

O modo como essas proposições "alternativas" são apresentadas nos documentos produzidos no âmbito da rede municipal de ensino de São Paulo a partir de 1986 indicam movimento de implementação do construtivismo em alfabetização na política curricular que então se desenhava, como aposta em uma "dupla promessa" dessa teoria: a sua identificação "[...] como uma teoria educacional progressista, satisfazendo portanto [...] critérios políticos exigidos por pessoas que, em geral, se classificavam como de 'esquerda'” (SILVA, 1996 p. 215); e a sua proposição de "[...] direção relativamente clara para a prática pedagógica, além de ter como base uma teoria da aprendizagem e do desenvolvimento humano com forte prestígio científico" (SILVA, 1996, p. 215). 
Essa "aposta" no construtivismo em alfabetização na rede municipal de ensino de São Paulo não se deu, porém, de maneira isolada. Em perspectiva eclética e conciliatória, as prescrições para o ensino inicial da leitura e a da escrita no período aqui analisado ocorreram de modo a justapor o construtivismo e os pressupostos do interacionismo linguístico, especialmente na visão de João Wanderley Geraldi, sintetizada em O texto na sala de aula: Leitura \& produção (1984). Sobre esse aspecto, ainda que diferentes tanto do ponto de vista epistemológico, quanto do ponto de vista político (MORTATTI, 2000), observamos que "construtivismo" e "interacionismo" convivem nos documentos aqui analisados como "complementares", o primeiro voltado ao período de "aquisição" da lecto-escrita, o segundo às práticas do ensino da língua para as crianças que já dominam o princípio alfabético da escrita, portanto, as que se apresentam aptas a ler e produzir textos.

Entendemos serem esses os principais aspectos que marcam a "chegada" do construtivismo em alfabetização na rede municipal de ensino de São Paulo, que concorre, em perspectiva ampliada, para o fenômeno de hegemonização dessa teoria no país. Nesse sentido, a despeito das dificuldades de se estudar historicamente o momento aqui enfatizado, dada sua identificação na contemporaneidade do não contemporâneo (DOSSE, 2011), buscamos problematizar a distância temporal que nos separa do passado não como intervalo morto, mas como geração de sentido (RICOEUR, 1985) em face da "tradição" que se "inventou" com o construtivismo em alfabetização no Brasil. Assim: "Antes de ser um depósito inerte, [entendemos essa] tradição como operação que só pode ser entendida dialeticamente na troca entre o passado interpretado e o presente interpretante. (RICOEUR, 1985, p. 210).

\section{Referências}

CANCLINI, Néstor García. Introdução à edição de 2001: as culturas híbridas em tempos de globalização. In: CANCLINI, Néstor García. Culturas Híbridas: estratégias para Entrar e Sair da Modernidade. São Paulo: Edusp, 2001.

CARVALHO, Silvia Aparecida Santos de. O processo de elaboração do Programa Ler e Escrever - prioridade na escola municipal de São Paulo. Tese (doutorado) - Universidade Estadual de Campinas, Faculdade de Educação - Campinas, 2016.

DOSSE, François. História do tempo presente e historiografia. Tempo e argumento. Revista do Programa de PósGraduação em História. v. 4, n. 1. P. 05-22, jan./jul. 2012.

FERREIRO, Emilia; TEBEROSKY, Ana. Los sistemas de escritura en el desarollo del niño. Cidade do México: Siglo Veintiuno Editores, 1979.

FERREIRO, Emilia; TEBEROSKY, Ana. Psicogênese da língua escrita. Tradução de Diana M. Linchestein et al. Porte Alegre: Artes Médicas, 1985a.

FERREIRO, Emilia. Reflexões sobre alfabetização. Trad. Horacio Gonzalez et al. São Paulo: Cortez, 1985b.

GERALDI, João Wanderley. O texto na sala de aula: Leitura \& produção. Cascavel: ASSOESTE, 1984.

JACOMINI, Márcia Aparecida. O ensino em ciclos e os educadores: rede municipal de ensino de São Paulo. Saarbrucken: Novas Edições Acadêmicas, 2016.

MELLO, Márcia Cristina de Oliveira. Emilia Ferreiro e a alfabetização no Brasil: um estudo sobre a Psicogênese da língua escrita. São Paulo: Editora Unesp, 2007.

MARINHO, M. A oficialização de novas concepções para o ensino de português no Brasil. 2001. 292f. Tese (Doutorado em Educação) - Instituto de Estudos da Linguagem, Universidade Estadual de Campinas, Campinas, 2001. 
MARSIGLIA, A. C. G. Um quarto de século do Construtivismo como discurso pedagógico oficial na rede estadual de ensino paulista. 2011. 228f. Tese (Doutorado em Educação) - Faculdade de Ciências e Letras, Universidade Estadual Paulista, Araraquara, 2011.

MELLO, Guiomar Namo. Discurso. Cadernos de Pesquisa, n. 45, p. 81-83, mai. 1983.

MORTATTI, Maria do Rosário Longo. Os órfãos do construtivismo. Revista IberoAmericana de Estudos em Educação, Araraquara, v. 11, n. esp. 4, p.2267-2286, 2016.

MORTATTI, Maria do Rosário Longo. Os sentidos da alfabetização: São Paulo 1876/1994. São Paulo: UNESP; Brasília: MEC, INEP, COMPED, 2000.

PESIRANI, Mariana Maíra Albuquerque. A constituição do discurso construtivista em documentos oficiais de referência curricular para a alfabetização produzidos nas décadas de 1980 e 1990. 2014. 93 p. Dissertação (Mestrado). Faculdade de Educação, Universidade de São Paulo, São Paulo, 2014.

REVAH, Daniel. Construtivismo: uma palavra no circuito do desejo. 2004. 530 p. Tese (Doutorado). Faculdade de Educação, Universidade de São Paulo, São Paulo, 2004.

RICOEUR, P. Tempo e narrativa 3: o tempo narrado. São Paulo: Editora WMF Martins

Fontes, 2010.

SÃO PAULO (Município). Programa de $1^{0} \mathrm{Grau}-1^{a}$ à $4^{a}$ série - versão preliminar. São Paulo: SME/DEPLAN, 1985a.

SÃO PAULO (Município). Programa de $1^{\circ} \mathrm{Grau}-1^{a} a ̀$ à $4^{a}$ série. São Paulo: SME/DEPLAN, 1985b (versão definitiva). SÃO PAULO (Município). Plano de Ação SUPEME: 1986/1988. São Paulo: SME-BES/DEPLAN, 1986a.

SÃO PAULO (Município). Considerações gerais sobre o ensino de língua portuguesa. São Paulo: SME-BES/ DEPLAN, 1986b

SÃO PAULO (Município). Alfabetização - textos de apoio: língua portuguesa e matemática. São Paulo: SME-BES/ DEPLAN, 1986C

SÃO PAULO (Município). Proposta integrada de treinamentos para 1987 -DEPLAN/DREMS. São Paulo: SMEBES/DEPLAN, 1987b

SÃO PAULO (Município). Propostas alternativas de alfabetização (destaque: Emilia Ferreiro). São Paulo: SMEBES/DEPLAN, 1987a.

SÃO PAULO (Município). Programa de Primeiro Grau - Ensino Regular: implementação de Português. São Paulo: Diário Oficial do Município (suplemento), 1987c.

SAVIANI, Demerval. História das ideias pedagógicas no Brasil. Campinas: Autores Associados, 2. ed., 2008.

SILVA, Tomaz Tadeu da. Identidades terminais: as transformações na política da pedagogia e na pedagogia da política. São Paulo: Vozes, 1996.

Recebido em: 02/02/2020

Aceito em: 15/03/2020 